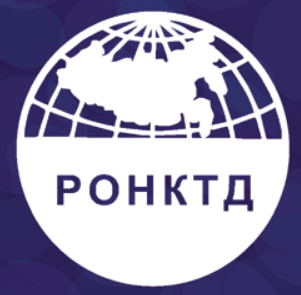

\title{
XXI ВСЕРОССИЙСКАЯ КОНФЕРЕНЦИЯ ПО НЕРАЗРУШАЮЩЕМУ КОНТРОЛЮ И ТЕХНИЧЕСКОЙ ДИАГНОСТИКЕ
}

\section{8 ФЕВРАЛЯ - 2 МАРТА 2017}

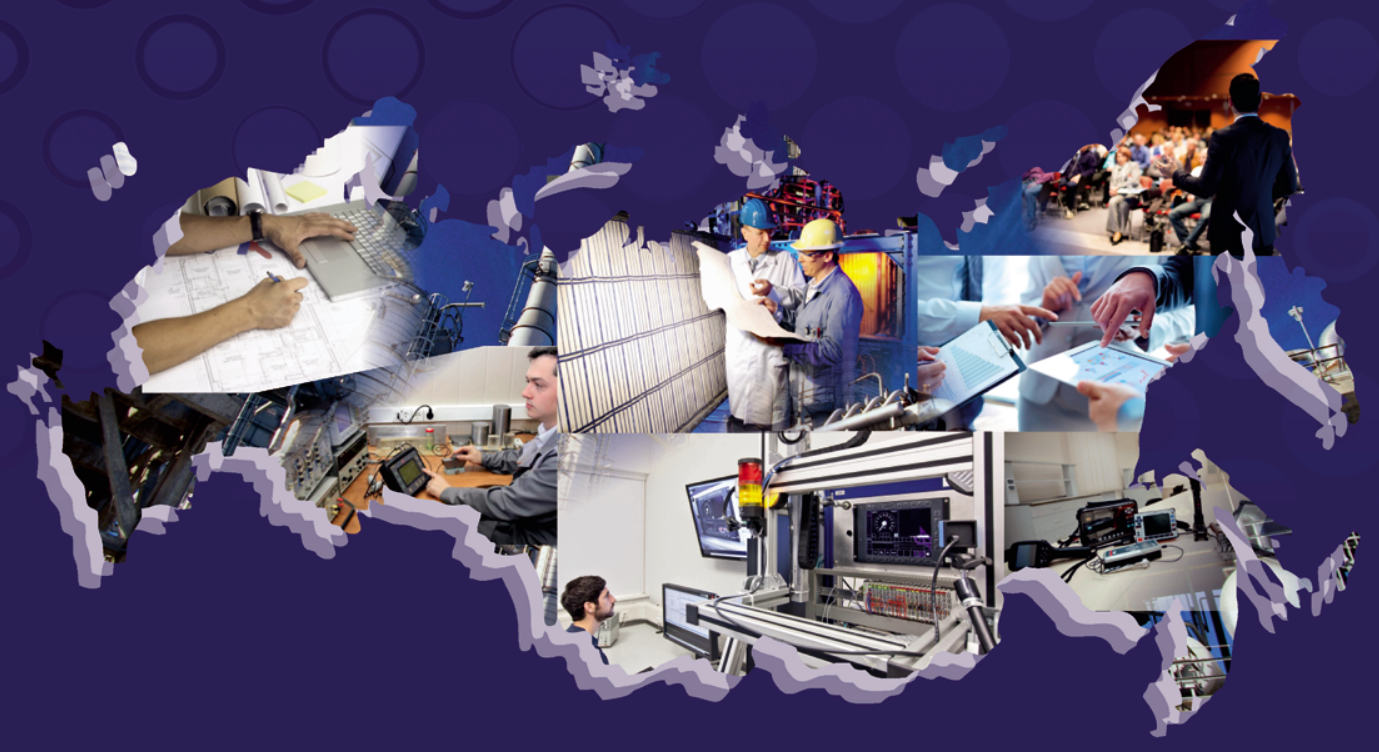

\section{СБОРНИК ТРУДОВ}


РОССИЙСКОЕ ОБЩЕСТВО

ПО НЕРАЗРУШАЮЩЕМУ КОНТРОЛЮ И ТЕХНИЧЕСКОЙ ДИАГНОСТИКЕ

\section{XXI ВСЕРОССИЙСКАЯ КОНФЕРЕНЦИЯ ПО НЕРАЗРУШАЮЩЕМУ КОНТРОЛЮ И ТЕХНИЧЕСКОЙ ДИАГНОСТИКЕ}

\section{СБОРНИК ТРУДОВ}

28 фревраля - 2 марта 2017 г.

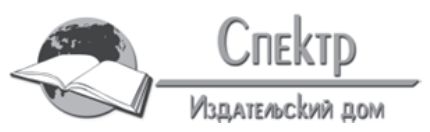

Москва, 2017 
УДК [681.518.54+620.19](035)

ББК 30.82-5я2

Д25

Д25 XXI Всероссийская конференция по неразрушающему контролю и технической диагностике: сборник трудов. Москва, 28 февраля 2 марта 2017 г. - М.: Издательский дом «Спектр», 2017. - 364 с.: ил.

ISBN 978-5-4442-0125-1

DOI 10.14489/4442-0125-1

Сборник содержит научные труды (тезисы и доклады), представленные на XXI Всероссийской конференции по неразрушающему контролю и технической диагностике. Изложены результаты работ ученых и специалистов российских и зарубежных фирм - мировых лидеров по производству средств неразрушающего контроля и технической диагностики. В состав сборника вошли работы по: акустической эмиссии; вибродиагностике; акустическим, магнитным, электромагнитным, оптическим, тепловым, микроволновым и радиационным методам неразрушающего контроля (НК) и технической диагностики (ТД); методам НК и ТД при оценке техногенной безопасности; обучению, аттестации и сертификации.

ББК 30.82-5я2

НАУЧНОЕ ИЗДАНИЕ

ХХІ ВСЕРОССИЙСКАЯ КОНФЕРЕНЦИЯ ПО НЕРАЗРУШАЮЩЕМУ КОНТРОЛЮ И ТЕХНИЧЕСКОЙ ДИАГНОСТИКЕ

\section{СБОРНИК ТРУДОВ}

28 февраля - 2 марта 2017 г.

Корректор А.И. Евсейчев

Инженер по компьютерному макетированию А.И. Евсейчев

Художественное оформление Н.И. Смольянина

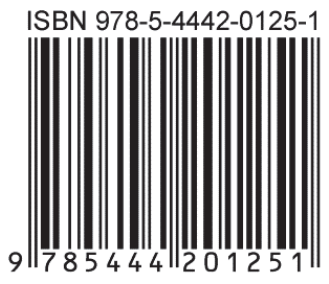

Сдано в набор 31.01.2017 г. Подписано в печать 15.02.2017 г. Формат $60 \times 901 \frac{1}{16}$. Бумага офсетная. Гарнитура Times. Печать офсетная. Уч.-изд. л. 23. Тираж 200 экз. Заказ

ООО «Издательский дом «СПЕКТР», 119048, Москва, ул. Усачева, д. 35, стр. 1. Тел.: (495) 5147650. Http://www.idspektr.ru. E-mail: info@idspektr.ru

Отпечатано в типографии ООО «Паблит» 127282, Москва, ул. Полярная, д. 31В, стр. 1 


\section{СОДЕРЖАНИЕ}

\section{Секция 1 \\ АКУСТИЧЕСКАЯ ЭМИССИЯ \\ Руководители секции: В. В. Муравьев, \\ С. В. Елизаров, В. И. Иванов}

1. Проведение АЭ контроля в условиях высокого уровня технологических шумов

Барат В. А., Елизаров С. В., Чернов Д. В., Бардаков В. В., Терентьев Д. А. . . ............................ 12

2. АЭ диагностика динамического оборудования

Бардаков В. В., Барат В. А., Терентьев Д. А., Елизаров С. В. . . . . 15

3. Прогнозирование прочности бетона в процессе твердения при помощи метода акустической эмиссии

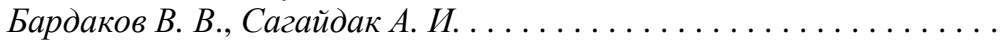

4. Идентификация типов дефектов и стадии их развития при акустико-эмиссионной диагностике металлических объектов

Бобров А. Л. ............................ 21

5. Об основных проблемах акустико-эмиссионной диагностики

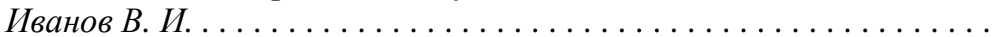

6. Возможности акустико-эмиссионного контроля процессов разрушения композиционных материалов

Иванов В. И., Матвиенко Ю. Г., Васильев И. Е., Елизаров С. В., Чернов Д. В. ........................... 26

7. Анализ данных акустической эмиссии при помощи искусственных нейронных сетей

Костенко П. П., Терентьев Д. А., Барат В. А. . . . . . . .....

8. Распознавание опасных развивающихся дефектов и их прогнозирование в процессе непрерывного мониторинга методом акустической эмиссии

Костюков А. В., Бойченко С. Н., Богомолов Д. Е. . . . . . . . . .

9. Интегральный дистанционный мониторинг фактического технического состояния ОПО I и II классов в нефтепереработке, нефтехимии и химии с применением метода и систем акустической эмиссии. Проблемы. Решения. Результаты

Махутов Н. А., Разуваев И. В..................

10. Перспективы АЭ мониторинга для оценки состояния производственных объектов и вспомогательного оборудования

Петерсен Т. Б., Шемякин В. В., Самохвалов А. Б., Курносов Д. А. . .

11. Локация источников АЭ при мониторинге промышленных объектов

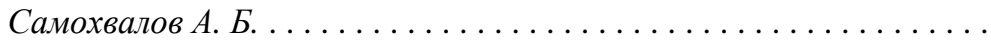


12. Применение акустико-эмиссионного метода неразрушающего контроля для оценки состояния композиционных материалов Чернов Д. В., Барат В. А., Елизаров С. В. ................

\section{Секция 2}

\section{АКУСТИЧЕСКИЕ МЕТОДЫ НК И ТД}

\section{Руководители секции: В. Г. Щербинский, В. Г. Шевалдыкин, Г. Я. Дымкин}

1. Применение спектрально-акустического метода для контроля качества ответственных деталей машин в условиях импортозамещения Абабков Н. В., Смирнов А. Н....................... 50

2. ЭМА преобразователь со стержневой импульсной магнитной системой для контроля качества точечной сварки Алехин С. Г., Бобров В. Т., Бобров С. В., Самокрутов А. А., Шевалдыкин В. Г...........................

3. Новые технологии сплошной ультразвуковой толщинометрии: от линейного сканирования до многосхемных методов цифровой фокусировки антенной решетки

Базулин А. Е., Базулин Е. Г., Вопилкин А. Х., Пронин В. В., Тихонов Д. С.

4. Применение фазированных антенных решеток для ультразвукового контроля тонкостенных аустенитных и разнородных сварных соединений

Базулин А. Е., Самарин П. Ф., Тихонов Д. С. ............. 60

5. Повышение качества ЦФА-изображений отражателей за счет применения антенной решетки с адаптивным протектором для учета неровной поверхности объекта контроля

Базулин Е. Г., Вопилкин А. Х., Тихонов Д. С. ..............

6. Исследование ЭМА метода акустической тензометрии

Бобров В. Т., Бобренко В. М., Гульшин А. В. ..............

7. Применение ультразвуковых волн Лэмба для контроля состояния алюминиевых сплавов

Бурков М. В., Бяков А. В., Еремин А. В., Любутин П. С. . . . . . . .

8. Применение прибора ПАКТ-04 для обследования теплообменных аппаратов

Быков С. П., Иншаков Д. В., Кузнеиов К. А. .............

9. Практические аспекты теории акустического поля преобразователей с фазированными решетками

Воронкова Л. В., Данилов В. Н. . . . . . . . . . . . . . . . . .

10. Идентификация дефектов в упругих пластинах на основе характеристик резонансного рассеяния бегущих волн

Глушков Е. В., Глушкова Н. В., Голуб М. В., Еремин А. А. . . . . . . 
11. Влияние аустенитного плакирующего слоя на основные параметры УЗК

Данилов В. Н., Разыграев Н. П., Разыграев А. Н., Цуканов М. В. . . 90

12. Оценка реальной чувствительности при приемочном ультразвуковом ЭХО-импульсном контроле рельсов

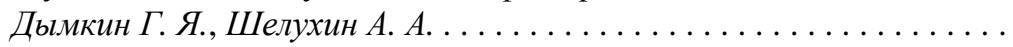

13. Определение эффективных упругих свойств композитных материалов и локализация в них неоднородностей с помощью бегущих волн

Еремин А. А., Глушков Е. В., Глушкова Н. В., Ламмеринг Р. . . . . . 14. Определение оптимального угла возбуждения волн Лэмба с применением фазированной антенной решетки

Исхужин Р. Р., Атавин В. Г. ..................

15. Использование алгоритма «Фокусировка на плоскость» для безэталонного измерения скорости ультразвука в крупногабаритных бетонных изделиях

Качанов В. К., Соколов И. В., Концов Р. В., Федоров М. Б. . . . . . 98

16. Расчет модели акустического тракта прямого преобразователя для отражателей простой геометрической формы

Козлов А. В., Козлов В. Н. . . . . . . . . . . . . . . . . .

17. Повышение точности измерения скорости ультразвука в материалах при поверхностном прозвучивании с помощью преобразователей с сухим точечным контактом

Козлов А. В., Козлов В. Н., Пичугин Н. К. . . . . . . . . . . .

18. Существующие типы и методы применения преобразователей с сухим точечным контактом в ультразвуковом контроле

Козлов А. В., Самокрутов А. А., Шевалдыкин В. Г. ..........

19. Зеркальный способ построения диаграмм направленности наклонных пьезопреобразователей в дополнительной плоскости Колпаков Е. Ю., Коновалов Н. Н., Рафиков Р. Х. . . . . . . . . . 20. Физико-математическое моделирование ультразвукового контроля фазированными антенными решетками для оценки показателей достоверности и выявляемости дефектов

Колпаков Е. Ю., Петров А. А., Коновалов Н. Н. . . . . . . . . .

21. Метод определения дефектов на основе теории искусственных нечетких нейронных сетей изделий из полимерных композиционных материалов

Котельников В. В., Козельская С. О., Рыков А. Н. . . . . . . . . . 106

22. Опыт комплексного применения электромагнитных и ультразвуковых методов дефектоскопии при диагностике технологических трубопроводов

Лисин Ю. В., Могильнер Л. Ю., Астахов В. Г. ............. 
23. Измерение размеров дефектов при ультразвуковом контроле длинномерных объектов

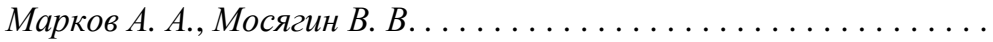

24. Исследование локальных напряжений и структуры в железнодорожных упрочненных рельсах методами акустоупругости и структуроскопии

Муравьев В. В.

25. Электромагнитно-акустический метод многократной тени при тензометрии и структуроскопии элементов насосных штанг Муравьева О. В., Муравьев В. В., Габбасова М. А., Зорин В. А., Петров К. В..............................

26. Особенности распространения и возбуждения волн при акустическом волноводном контроле труб

Муравьева О. В., Мыцкин Ю. В., Леньков С. В.............

27. Варианты контроля деталей и конструкций из полимерных композиционных материалов ультразвуковыми методами прохождения

Мурашов В. В., Яковлева С. И....................

28. Ультразвуковой акустический контроль изделий из полимерных композиционных материалов

Рыков А. Н.

29. Антенная решетка с лестничной призмой для ультразвуковых дефектоскопов

Самокрутов А. А., Соколов Н. Ю., Шевалдыкин В. Г. . . . . . . . .

30. Система автоматизированного ультразвукового контроля сварных соединений трубопроводов и металлоконструкций

Суворов В. А., Самокрутов А. А., Шевалдыкин В. Г. . . . . . . . . .

31. Мобильные комплексы на комбинированном ходу для диагностики пути и обслуживания инфраструктуры железнодорожного транспорта

Тарабрин В. Ф..........................

32. Сверхскоростной ультразвуковой контроль рельсового пути

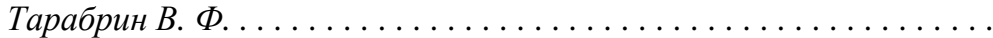

33. Методология автоматизированного ультразвукового контроля с определением размеров дефектов

Тихонов Д. С. ...............................

34. Современный автоматизированный комплекс на ЦФА-дефектоскопе АВГУР-АРТ для высокопроизводительного контроля при строительстве трубопроводов

Тихонов Д. С., Ромашкин С. В. ..................

35. Повышение эффективности методов ультразвукового контроля в потоке производства электросварных труб

ткаченко А. А. ..................................... 


\section{Секция 3}

\section{ВИБРОДИАГНОСТИКА}

\section{Руководители секции: Г. В. Зусман, В. Н. Костюков}

1. Новая методика диагностирования подшипниковых узлов рельсового подвижного состава в процессе движения

Басакин В. В., Костюков В. Н., Костюков Ал. В., Казарин Д. В. .. .

2. Методика диагностики электротехнических устройств, содержащих обмотки и магнитопровод

Городнов А. В., Засухин В. В., Рущиинский В. Н., Тренин С. А. .....

3. Совершенствование методов и средств вибродиагностики колесно-моторных блоков подвижного состава

Зайцев А. В., Костюков Ал. В., Казарин Д. В. . . . . . . . . . . . . .

4. Результаты экспериментальных исследований, подтверждающие возможность регистрации механических колебаний намагниченных тел с помощью внешней обмотки

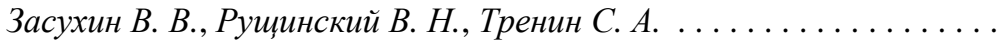

5. Вибрационный измерительный и диагностический канал КД8700 и резонансный метод контроля подшипников

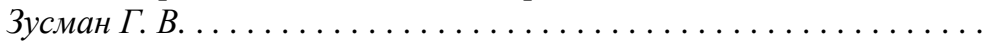

6. Опыт применения параметров характеристической функции для диагностики и мониторинга технического состояния подшипников качения

Костюков В. Н., Костюков А. В., Бойченко С. Н. ...........

7. Автоматические системы мониторинга «здоровья» оборудования производственно-транспортного комплекса, обеспечивающие высокую безопасность и эффективность

Костюков В. Н., Костюков Ан. В., Костюков Ал. В., Бойченко С. Н., Казарин Д. В.........................

8. О дополнительных требованиях к системам виброконтроля и мониторинга технического состояния турбоагрегатов ТЭС и АЭС Куменко А. И., Кузьминых Н. Ю. ................

9. Критерии надежности и мониторинг технического состояния мощных турбоагрегатов с использованием статических и динамических сил в опорах валопроводов

Куменко А. И., Кузьминых Н. Ю., Тимин А. В.............

10. Мониторинг распределенной неуравновешенности экспериментального ротора с использованием датчиков вала

Куменко А. И., Кузьминых Н. Ю., Тимин А. В...........

11. Обобщенная модель механизма формирования и структуры виброакустического сигнала поршневой машины Науменко А. П., Костюков В. Н. . . . . . . . . . . . . ... . 
12. Повышение эффективности эксплуатации насосно-компрессорного оборудования за счет применения систем диагностики. Разработка отечественной системы диагностики САНПО в рамках импортозамещения

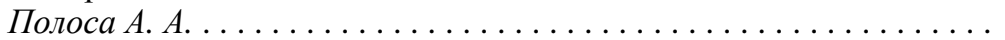

13. Концепция развития вибрационной диагностики при аутсорсинговом обслуживании локомотивов в условиях сервисных локомотивных депо

Семенов А. П., Шкуратеикий А. В. ................

14. Распознавание механических дефектов мощных турбокомпрессоров средствами стационарной системы «САДКО»

Соколов Д. В................................

\section{Секция 4}

\section{МАГНИТНЫЕ И ЭЛЕКТРОМАГНИТНЫЕ МЕТОДЫ НК И ТД}

\section{Руководители секции: Я. Г. Смородинский, В. А. Сясько, Э. С. Горкунов}

1. Двухпараметровое устройство контроля литого остеклованного микропровода

Антипов В. Б., Дорофеев И. О., Дунаевский Г. Е., Хлестунов А. П., Шиильной В. Ю. ........................

2. Как перейти от неразрушающего контроля к измерению напряжений в стальных конструкциях методом магнитных шумов?

Венгринович В. Л., Винтов Д. А., Прудников А. Н., Подугольников П. А., Рябиев В. Н. . . . . . .................

3. Вихретоковый фазовый метод измерения толщины металлических покрытий. Метрологическое обеспечение калибровки и поверки толщиномеров и мер толщины покрытий

Голубев С. С., Сясько В. А., Смирнова Н. И., Складановская М. И. ...

4. Новые исследования и технологии магнитодинамического контроля длинномерных объектов

Марков А. А., Антипов А. Г. .................

5. Анализ условий использования измерений магнитных параметров сталей и чугунов на частных петлях магнитного гистерезиса для контроля структуры изделий машиностроения и металлургии Сандомирский С. Г........................

6. О коэффициенте корреляции между результатами измерения и расчета твердости сталей при «многопараметровых» методах контроля Сандомирский С. Г. .........................

7. Синтез структурочувствительных магнитных параметров сталей из параметров их предельной петли магнитного гистерезиса Сандомирский С. Г. ........................ 
8. Опыт внедрения автоматизированных систем мониторинга стальных канатов

Слесарев Д. А., Сухоруков Д. В., Шпаков И. И. . . . . . . . . . . .

9. Диагностика ответственных объектов рельсового подвижного состава с применением роботизированных средств НК

Сляднев А. М. . . . . . . . . . . . . . . . . . . . . . . . .

10. Многофункциональный роботизированный комплекс для диагностики объектов сложной формы

Сляднев А. М. .............................

11. Моделирование и оптимизация параметров магнитной системы MFL-преобразователей

Сясько В. А., Пудовкин О. П. . . . . . . . . . . . . . . . . . . . .

12. Особенности импульсного размагничивания деталей из магнитотвердых материалов

Шарин П. А., Чуприн А. В., Чуприн В. А., Сосницкая Т. А. ......

\section{Секция 5}

\section{МЕТОДЫ НК И ТД ПРИ ОЦЕНКЕ ТЕХНОГЕННОЙ БЕЗОПАСНОСТИ}

\section{Руководители секции: Н. А. Махутов, В. И. Иванов, В. А. Барат}

1. Неразрушающий контроль герметичности малогабаритных газонаполненных приборов

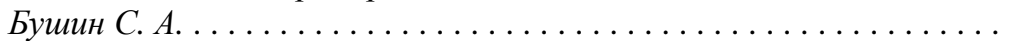

2. Техническая диагностика и мониторинг за состоянием оборудования и конструкций на современном этапе развития

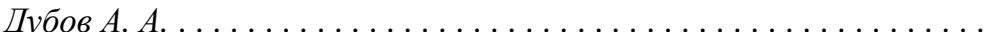

3. О требованиях к НК при оценке риска аварии

Иванов В. И., Мусатов В. В., Сазонов А А.

4. О нормативной базе системы неразрушающего контроля на опасных производственных объектах

Колпаков Е. Ю., Дергачев А. Н., Коновалов Н. Н. . ...........

5. Влияние переменного режима эксплуатации на механические характеристики, образование и развитие дефектов КРН магистрального газопровода

Коннов Вл. Вл., Конюхов Ю. А. . . . . . . . . . . . . . .

6. К вопросу о комплексной оценке НДС и прогнозировании остаточного ресурса газопроводов

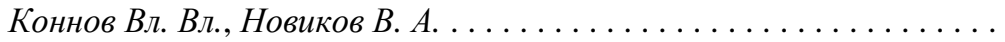

7. Метод анализа независимых компонент при выделении полезного сигнала при мониторинге сложных объектов

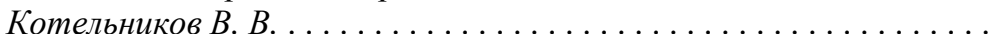


8. Совершенствование методик контроля систем молниезащиты и заземления для обеспечения промышленной безопасности объектов перекачки нефти

Могильнер Л. Ю., Владова А. Ю., Панкратов А. Н. . . . . . . . . . .

9. Измерение механических свойств методом инструментального индентирования. Методические и метрологические аспекты. Оценка функции формы индентора

Сясько В. А., Уманский А. С., Кондратьев А. В. . . . . . . . .

\section{Секция 6}

\section{ОБУЧЕНИЕ, АТТЕСТАЦИЯ И СЕРТИФИКАЦИЯ}

\section{Руководители секции: Н. Н. Коновалов,}

Б. В. Артемьев, С. Г. Копытов, А. В. Муллин

1. Сертификация персонала неразрушающего контроля для проведения работ в соответствии с требованиями DS-1 и ASME

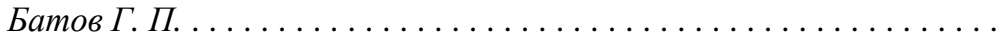

2. Подготовка персонала неразрушающего контроля в НОАП НК ООО «Энергодиагностика»

Колокольников С. М., Дубов А. А. .....................

3. Особенности подготовки специалистов по анализу дефектоскопической информации

Марков А. А., Молотков С. Л., Максимова Е. А............

4. ISO 9712:2012. Инспекционный контроль и процедура продления сертификации. Как соответствовать стандарту ISO/IEC 17024: 2012? Муллин А. В., Стрижаков В. М. ..................... 320

5. Опыт взаимодействия органа по сертификации персонала с экзаменационными центрами и уполномоченными органами по квалификации

Муллин А. В., Стрижаков В. М. .................

\section{Секция 7}

\section{ОПТИЧЕСКИЕ, ТЕПЛОВЫЕ, МИКРОВОЛНОВЫЕ МЕТОДЫ НК И ТД}

\section{Руководители секции: В. П. Вавилов, Е. В. Абрамова, В. И. Матвеев}

1. Теоретическая модель тепловыделения при ударе в тканный образец

Будадин О. Н., Каледин В. О., Козельская С. О., Шлагов Д. А. . . . . 
2. Волоконно-оптические нервоподобные интеллектуальные сенсорные системы реального времени для неразрушающего контроля объектов в экстремальных условиях

Буймистрюк Г. Я., Николаев В. Н. . ................

3. Устройство для контроля композиционных материалов методом цифровой ширографии

Бурков М. В., Бяков А. В., Любутин П. С. . . . . . . . . .

4. Тепловой контроль в Томском политехническом университете

Вавилов В. П. ..............................

5. Анализ процесса закрытия усталостной трещины на мезомасштабном уровне методом корреляции цифровых изображений Еремин А. В., Панин С. В., Сундер Р. . . .................

6. Определение утечек газа с использованием Фурье-спектрорадиометрических систем

Коннов Вл. Вл., Конюхов Ю. А. ...................

7. Состояние и развитие способов стимуляции теплового контроля

Матвеев В. И. ...........................

8. Автоматизация измерений толщины покрытий микроволновым методом

Матвеев В. И., Бажанов А. С. .....................

9. Определение порога дефектоскопии при контроле изделий из композиционных материалов

Рьков А. Н.............................

\section{Секция 8}

\section{РАДИАЦИОННЫЕ МЕТОДЫ НК И ТД (ВКЛЮЧАЯ РАДИАЦИОННУЮ ТОМОГРАФИЮ)}

Руководители секции: Б. В. Артемьев, Л. В. Владимиров, А. В. Степанов

1. Восстановление парка радиационных толщиномеров Артемьев Б. В., Артемьев И. Б., Владимиров Л. В. . . . . . . . . . . 2. Применение портативной гамма камеры при обращении с РАО Артемьев Б. В., Иванов О. П., Потапов В. Н., Степанов В. Е. . . . . 3. Промышленная томография крупногабаритных объектов Бориков В. Н., Чахлов С. В., Рычков М. М., Штейн А. М., Смолян-

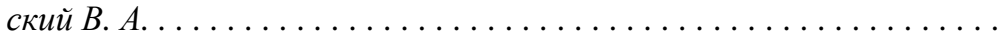
4. Реверсивные технологии на базе 3D рентгеновской томографии для аддитивной концепции Венгринович В. Л. .........................

5. Анализ возможностей использования дозиметрических приборов при регистрации импульсного рентгеновского излучения Владимиров Л. В., Буклей А. А., Артемьев Б. В., Охрименко С. Е.,

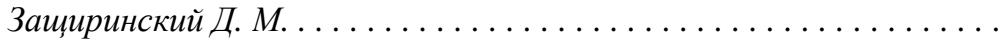

